\title{
Análisis histórico documental de una asesina en serie latinoamericana
}

\author{
Historical documentary analysis of a Latin American serial killer \\ Análise documental histórica de um serial killer latino-americano
}

Catalina Villafuerte

cata_cmvr@yahoo.com

https://orcid.org/0000-0003-1066-8875

Universidad Central del Ecuador, Quito, Ecuador
Estuardo Paredes Morales

estuardoparedesmorales@yahoo.es

https://orcid.org/0000-0002-9722-5091

Universidad Central del Ecuador, Quito, Ecuador
RESUMEN

El objetivo de este documento fue realizar un recorrido histórico de la conceptualización de la Psicopatía. Especialmente de las distintas explicaciones que se han construido alrededor de la Psicopatía femenina, a través del tiempo, desde las Ciencias Humanas, Sociales y Médicas y sus diversas corrientes; $y$ la influencia de los distintos enfoques de Género en las mujeres. También busca explicar desde las distintas dimensiones teóricas aquí expuestas, el comportamiento delincuencial de la asesina en serie, colombiana, María Concepción Ladino, alias "La bruja asesina" articulando de esta manera aspectos conceptuales y de Género con elementos históricobiográficos y otros específicos, como el modus operandi o el móvil que pudieron subyacer las acciones crueles y despiadadas ejecutas por esta mujer.

Palabras clave:

Psicopatía; asesina en serie; criminología; delincuente; género

ABSTRACT

RESUMO

The objective of this document was to carry out a historical tour of the conceptualization of Psychopathy. Especially of the different explanations that have been built around female psychopathy, through time, from the Human, Social and Medical Sciences and its various currents; and the influence of the different gender approaches in women. It also seeks to explain, from the different theoretical dimensions presented here, the criminal behavior of the Colombian serial killer, María Concepción Ladino, alias "La bruja asesina", thus articulating aspects conceptual and Gender with historical-biographical and other specific elements, such as the modus operandi or the motive that could underlie the cruel and ruthless actions carried out by this woman.

Key words:

Psychopathy; serial killer; criminology; offender; gender
O objetivo deste documento foi realizar um percurso histórico da conceituação da Psicopatia. Principalmente das diferentes explicações que se construíram em torno da psicopatia feminina, ao longo do tempo, desde as Ciências Humanas, Sociais e Médicas e suas diversas correntes; e a influência de diferentes abordagens de gênero nas mulheres. Também busca explicar, a partir das diferentes dimensões teóricas aqui apresentadas, o comportamento criminoso da assassina em série colombiana, María Concepción Ladino, também conhecida como "La bruja asesina”, articulando assim aspectos conceituais e de gênero com elementos históricobiográficos e outros específicos. modus operandi ou o motivo que poderia estar por trás das ações cruéis e implacáveis realizadas por esta mulher.

Palavras-chave: Psicopatia; assassino em série; criminologia; ofensor; Gênero

sexual 


\section{INTRODUCCIÓN}

Estudiar la Psicopatía como trastorno de la personalidad es adentrarse en un tema controversial de gran interés clínico y también legal- forense. Implica entender la maldad humana y los comportamientos que derivan de ella, a profundidad, porque al parecer el Sujeto Psicópata es la expresión máxima de la maldad humana tanto en términos cognitivos como emocionales y comportamentales. Las evidencias científicas, en la actualidad, han demostrado, hasta la saciedad, que la Psicopatía es un factor predictor de primera magnitud de la conducta trasgresora de la normativa social y legal.

Distintos enfoques de la Psiquiatría y la Psicología han intentado explicar este trastorno lo largo de la historia en colaboración con otras ciencias como la Antropología, la Criminología y la Sociología. Partiendo de la influencia de factores biológico- funcionales y evolutivos en unos casos; y desde enfoques centrados en la incidencia del aprendizaje, el apego inseguro en edades tempranas y el influjo de los contenidos profundos de la psique humana, entre otros.

Adicionalmente, la mayoría de estudios de Género, relacionados con la Psicopatía, la han analizado adscrita a los hombres. Entendiéndola como expresión de masculinidades construidas alrededor de la violencia, el control, el riesgo, la razón, la actividad y el hermetismo emocional, interpretados, como valores fundamentales de lo masculino y la masculinidad (Chávez, 2012).

Solo en los últimos años, la Criminología ha centrado sus esfuerzos en demostrar desde una perspectiva de género menos sesgada, la realidad de las mujeres psicópatas, como autoras de delitos; alejándose, en este análisis, de la influencia de los estereotipos tradicionales de feminidad y de los roles cotidianos de las mujeres, que invisibilizan su potencial delictivo y de peligrosidad, encasillándolas en el espacio privado y como esencialmente bondadosas, pacientes, conciliadoras, afectuosas, maternales y dependientes de la opinión de otros (Chávez, 2012).

Este mismo sesgo genérico que unas veces invisibiliza a las mujeres Psicópatas, otras veces las masculiniza, mientras coloca a las demás mujeres como sujetos garantes de las normas sociales, en el núcleo familiar, de "naturaleza" contraria a la de los hombres. De ahí que son consideradas doblemente desviadas, aquellas que presentan conductas delictivas de cualquier tipo. Desde un enfoque sociológico, rompiendo con el rol y la imagen que la sociedad espera de ellas y desde el Derecho, desviándose de la norma legal que constituye el delito per se (Constant, 2016, p.151).

Históricamente, la Psicopatía ha sido considerada una patología muy compleja pero además esencialmente masculina y presente casi exclusivamente en los hombres. Esta complejidad ha generado extensas y profundas discusiones científicas a lo largo del tiempo.

Ya en el siglo XIX Prichard (1835) conceptualizó este trastorno como "una forma de perturbación mental en el que las funciones intelectuales parecen estar intactas, mientras que el trastorno se manifiesta únicamente por el estado de los sentimientos, temperamento o hábitos. En estos casos, los principios morales o activos de la mente están pervertidos o depravados; el poder de autodominio se ha perdido o está muy alterado, y el individuo, "hombre", es incapaz no sólo de hablar o razonar sobre los temas que se le proponen, sino de conducirse con decencia y propiedad en los asuntos de la vida".

De esta forma, el autor diferencia la Psicopatía de la esquizofrenia y el retraso mental. Ambas condiciones médicas, considerados para la época, como patologías psiquiátricas que hacían de los sujetos que las padecían, peligrosos y amenazantes para la sociedad; comprometiendo, a diferencia 
de la psicopatía, el intelecto y al igual que esta, la volición y el afecto. Consecuentemente Prichard (1835) sugiere que las funciones mentales (intelecto, afectividad, voluntad) se podían enfermar de manera independiente. Concepto revolucionario, para ese momento del desarrollo, de las Ciencias relacionadas con el funcionamiento psíquico, pero que omitía a las mujeres, en su conceptualización y análisis.

Posteriormente, a inicios del siglo XX, el psiquiatra alemán Emil Kraepelin (1903) en su obra Psychiatrie: Ein Lehrbuch, comenzó a hablar de los estados psicopáticos y, sobre todo, de las personalidades psicopáticas. Siendo el primero en advertir que los psicópatas no se encontraban recluidos dentro de los sanatorios mentales ni tampoco se circunscribían, únicamente al submundo delincuencial y las prisiones.

Este autor, sugirió que muchos psicópatas son capaces de lograr niveles de adaptación social aceptable y ubicarse en espacios de poder, desde donde provocan daño, sufrimiento y dolor a gran cantidad de personas, incluyendo naciones completas. Estos sujetos, "hombres", hacen uso de su carisma, encanto y seducción, para obtener dinero, poder y control a cualquier precio.

En el caso de las mujeres, el primer estadio de estudio y comprensión de la psicopatía femenina comprendería los siglos XVIII y XIX. En este lapso de tiempo se consideró a la mujer delincuente como un ser perverso e inmoral y biológicamente diferente a las otras mujeres (Santilla Esqueda, 2016). Construyéndose un sujeto "Mujer Psicópata" en base a los estereotipos tradicionales, establecidos desde la religión, la costumbre y el androcentrismo propios de la época.

En un segundo estadio de entendimiento del fenómeno, predominan las tesis biologicistas como la del atavismo criminal de Lombroso y Ferrero (1895) según las cuales, una mujer delincuente es una mujer que no ha evolucionado adecuadamente y por lo tanto presenta rasgos primitivos, mismos que la llevan a cometer actos ilícitos y atroces. Estos autores describían rasgos físicos en las mujeres delincuentes que les asemejaban a los antepasados menos evolucionados y a los simios, como la prueba física de su inferioridad; es decir, estaban estancadas en un estadio previo del desarrollo humano (López, 2013).

Entre 1930 y 1950, se configura un escenario intelectual influenciado por el Psicoanálisis, la Sociología, el Derecho, la Biología y la Psiquiatría. Las mujeres son consideradas una amenaza para las normas impuestas por el sistema patriarcal heteronormado de ese momento. En una sociedad que paulatinamente experimenta un cambio en los roles de las mujeres y un ingreso progresivo de estas, a espacios, tradicionalmente, ocupados por hombres, se criminalizan los comportamientos femeninos $y / o$ de las mujeres que suceden en el espacio público. Más aún aquellos ilegales, considerados, consecuencias negativas directamente relacionadas con la Emancipación Femenina.

Los nuevos comportamientos femeninos, sobre todo aquellos que pudieran contravenir con el ideal femenino hegemónico, son considerados subversivos. Se empieza a tipificar las características psicológicas y fisiológicas de las delincuentes, así como los tipos de crímenes cometidos por ellas.

Era común entre criminólogos sostener que las mujeres podían convertirse en delincuentes en razón tanto del entorno social, así como de las características propias de su sexo (físicas, psicológicas, biológicas y hormonales). Las teorías de la imitación del hombre y de la emancipación femenina proponían que los cambios sociales producto de la modernización que promovían la participación de las mujeres en los espacios públicos, eran factores de riesgo, pues podían incitarlas al crimen (Lima Malvido, 1991, p.81-106). 
Actualmente, a pesar de que la Criminología ha llegado a concebir el género como uno de los mayores correlatos del delito, aún no ha equiparado cualitativa o cuantitativamente, en cantidad o calidad, los estudios de las mujeres Psicópatas en relación a los existentes sobre los hombres con este mismo trastorno. De igual forma, si bien, la Criminología reconoce que el género y el delito se conectan histórica y transculturalmente, esto no ha incidido significativamente en el desarrollo de esta disciplina en lo que a la Psicopatía femenina se refiere.

Se ha constatado a lo largo del tiempo que los varones manifiestan una propensión mayor a la comisión de ilícitos que las mujeres. Esto ha provocado que los estudios Criminológicos se centren en el estudio del "hombre delincuente". Consecuentemente se produjo una "ceguera de género", inherente a este campo de estudio (Cecil, 2006, p. 171) lo que, a la larga, ha limitado el crecimiento de la disciplina, pero también la posibilidad de conocer más acerca la psicopatía femenina.

Estudios, como los de Sheldon Itzkowitz y Elizabeth F. Howell (2020) plantean que la maldad humana implica "un comportamiento depredador, desenfrenado, despiadado y destructivo, llevado a cabo sin culpa, remordimiento o preocupación por las víctimas. "Un comportamiento que nos genera incredulidad ante esa capacidad humana de destructividad deliberada.

Estas expresiones negativas extremas de la naturaleza humana pueden explicarse desde varios enfoques. La teoría estructural, propuesta por Freud (1964), explica la psicopatía, como una patología del Superyó, que se produce cuando la autoridad parental ha sido inexistente, inconsistente o demasiado severa. Según Kaufman (1958), para sentir culpa hace falta un estado de tensión entre el Yo y el Superyó. La imposibilidad de sentir culpa de los psicópatas nos mostraría la patología que tienen en el Superyó. Esta tensión en ellos no existe y esto les permitiría comportarse de forma despiadada, depravada o cruel, sin sentir remordimiento; aspecto clave en la comprensión de la conducta psicopática.

El resultado de la influencia del yo y el súper yo sobre los instintos del sujeto, es la empatía o capacidad de ponerse en los pies del otro y por tanto de conectarse con el sufrimiento de una víctima. En los psicópatas esta interacción es nula o muy deficiente. Para Shapiro (1965) el psicópata es consciente de los valores morales, pero no le interesan. Estos valores, plantea este autor, son abstractos y requieren un desarrollo emocional y cognitivo del que carecen los psicópatas.

En este sentido, al ser las mujeres psicópatas, primitivas como lo propone Lombroso (1895) su capacidad de desarrollo emocional y cognitivo sería limitado; y esta limitación, la causa de su comportamiento impulsivo y despiadado, así como también de su incapacidad de autorreflexión.

Adicionalmente, Freud (1948, p. 350) explica la Psicopatía femenina aduciendo que la anatomía de las mujeres es inferior a la de los hombres. Seguidamente, están destinadas a ocupar una posición inferior en el status social, adjudicándoles el papel de madres y esposas. Como un continuo de esta visión de las mujeres, el comportamiento delictivo en ellas, resultaría de factores psicógenos que pudieran incidir en el aparecimiento de dichas conductas, como conflictos no resueltos, el Electra, una relación pobre con el padre o una actitud hostil hacia la madre.

En el siglo XIX Freud hablaba, además, de la "envidia del pene" de las mujeres, para sustentar, su planteamiento de que están frustradas por estar incompletas y que esta condición podría incidir en el desarrollo de conductas psicopáticas. En la actualidad, se ha demostrado que los factores genéticos 0 biológicos no tienen ningún tipo de determinación directa en el ejercicio de la 
violencia por parte de hombres o mujeres (Rovelo y Borja, 2019). García (2019) apoya esta afirmación al buscar las respuestas a la diferencia entre los índices de violencia masculinos y femeninos en la educación y en los procesos de socialización, fundamentalmente.

Desde la teoría del apego, según apunta Itzkowitz (2020), podemos observar que en los psicópatas falta la función reflexiva y la empatía emocional que se desarrollan en el apego seguro (del niño con sus cuidadores primarios) que ocurre cuando estos le han brindado, cariño, cuidado, aceptación y amor incondicional durante los primeros meses de vida.

La disociación y la alteración en estas funciones, así como en la falta de regulación del afecto, aparecen especialmente cuando ha sucedido una relación traumática entre el niño y sus cuidadores a edades tempranas; generalmente marcada por la negligencia, la violencia o el rechazo. Esto provocará un apego ansioso, evitativo o ambos, consecuentemente, el resultado será un apego desorganizado en el cual el niño percibirá el mundo como un lugar inseguro y peligroso. Al crecer, su mecanismo de afrontamiento ante una realidad amenazante será el ataque por adelantado con el fin de evitar ser dañado primero. Desde esta concepción del mundo y de sí mismo en él, el psicópata justificará su comportamiento transgresor.

Analizando el vínculo establecido entre madre e hijos y concretamente, el construido entre la madre y las hijas, se lo considera determinante, a la hora de transmitir el modelo de subordinación femenina a la autoridad masculina (en un contexto patriarcal). Además, la madre tiene una importante función legitimadora de las actividades delictivas de los hijos, impidiendo el arrepentimiento y a veces, reforzando la predisposición a delinquir (Paoli, 2003; Hernández, 1997, p. 583).

El análisis anterior, deja entrever la relación existente entre el proceso de aprendizaje, como lo propone Bandura (1987a, 1987b; Bandura y Ribes, 1975; Bandura y Walters, 1983) y el establecimiento y calidad del vínculo afectivo entre los cuidadores primarios y el niño. Este enfoque rechaza la concepción innata de la agresividad humana y la base genética del temperamento o la personalidad; trasladando el origen de la violencia al aprendizaje por modelado que se produce en las relaciones interpersonales.

Si las conductas imitadas y posteriormente reforzadas por estos cuidadores, otros familiares, pares, u otros agentes sociales y comunitarios, son prosociales, se producirá el modelamiento y el aprendizaje se consolidará. Burgess y Akers (1966) y Akers (1997) explican en qué medida los individuos aprenden a comportarse de modo violento o como delincuentes, a través del aprendizaje del modelado de la conducta, es decir, la observación, su imitación y posterior reforzamiento positivo.

En el caso de las mujeres, en la mayoría de entornos, incluso en los más violentos y como consecuencia del patriarcado y los roles de género construidos y consolidados por su modelo de organización social, se refuerzan conductas orientadas al cuidado de los otros y también de sacrificio personal. Además se las vincula en menor grado que a los varones en actividades violentas, ilegales o ilícitas. De esta forma se explicaría, desde este enfoque, el actuar ilícito y su normalización en un porcentaje pequeño de mujeres.

En cambio, su inmersión cada vez mayor en actividades consideradas otrora, adscritas a los varones, podría ser un factor que esté incidiendo en el aumento paulatino de la psicopatía femenina y en la participación progresivamente mayor de las mujeres en actividades ilegales y/o ilícitas.

Desde otra arista del análisis, Wellons (2012) basado en el estudio de los factores de la personalidad, destaca la existencia de dos tipos de psicópatas: primarios y secundarios. Los primeros, 
sujetos considerados socialmente triunfadores, suelen ser carismáticos, encantadores y con altas capacidades cognitivas. Su inteligencia, encanto superficial y habilidades de manipulación, no solo puede llevaros a alcanzar espacios de poder, sino además a desvirtuar su maldad; interpretándola como astucia o liderazgo. En cambio, los segundos suelen ser más impulsivos, menos calculadores y muy desorganizados, de modo que tienden a quebrantar la ley constantemente. Les cuesta adaptarse a las normas sociales y legales. Con frecuencia, estos últimos, habitan las prisiones.

Entre las mujeres psicópatas, Carabellese et al. (2020) hallaron una prevalencia relativamente alta de trastornos de personalidad del grupo B, conformado por los trastornos narcisista, antisocial, histriónico y límite, de la personalidad, destacando este último sobre los demás (Ibíd, 2020, p.7). Se infiere que el trastorno límite y el trastorno antisocial comparten la tendencia al consumo problemático de drogas, la impulsividad y la inestabilidad emocional; por lo tanto, la tendencia a presentar promiscuidad, comportamientos sexuales peligrosos y transgresores de la ley. Maurer et al. (2016) apoyan esta afirmación, justificándola en la naturaleza impulsiva y agresiva que comparten ambos trastornos.

Sprague et al. (2012) sugieren la posibilidad de considerar el TLP como una variante secundaria de psicopatía femenina. Siguiendo la línea de un estudio desarrollado por Hicks et al. (2010), las mujeres psicópatas se dividirían en dos subcategorías basándose, en sus características de personalidad y similares a las propuestas por Wellons (2012) para los psicópatas en general: primarias y secundarias. Estas últimas son las que guardarían relación con el TLP, pues se distinguirían por una impulsividad extrema, agresividad, conductas suicidas, trastorno de estrés postraumático (TEPT) y abuso de sustancias, entre otras características.

En cambio, las mujeres con trastorno de personalidad narcisista y/o histriónico guardarían relación con las psicópatas primarias, ya que ellas a través de su carisma, encanto, inteligencia, capacidad de manipulaciónyseducción son capaces de alcanzar sus ambiciosos, e inescrupulosos objetivos y/o espacios de poder.

EL DSM V (Manual Diagnóstico y Estadístico de los Trastornos Mentales de la Asociación Americana de Psiquiatría) propone una clasificación de los Trastornos de Personalidad. Stone (2020,) considera que existe un déficit en este estudio. Afirma que confunde descriptores con rasgos y que por tanto es más útil pensar en las personalidades negativas como un continuo de menor a mayor gravedad y buscar los rasgos de cada una de ellas.

De todas formas, de acuerdo a los criterios diagnósticos de este manual, lo más cercano a la descripción de la Psicopatía es el trastorno antisocial de la personalidad. Los sujetos que lo padecen suelen cometer actos imprudentes, de explotación, engañosos e ilegales con el fin de obtener beneficio o placer personal sin sentir remordimiento o culpa. Frecuentemente, justifican o racionalizan su comportamiento, culpabilizando a la víctima por ser tonta o indefensa.

En cuanto a la prevalencia, el DSM-5 (2013) refiere que el trastorno de personalidad antisocial, es más frecuente entre los hombres que entre las mujeres, en una relación de (6:1) y que hay un fuerte componente hereditario en su padecimiento. La prevalencia disminuye con la edad, lo que sugiere que los pacientes pueden aprender con el tiempo a cambiar su mal comportamiento.

La mayoría de ellos presentan, concomitantemente, trastornos relacionados con el consumo de Sustancias Psicoactivas. Con frecuencia, suelen padecer trastornos relacionados con el control de impulsos, hiperactividad, o un trastorno límite de la personalidad, mismo que como se mencionó antes, presenta mayor prevalencia en las mujeres.

Desde el enfoque neurobiológico también se explica la Psicopatía. Birmauer et al, (2005) y Flor 
et al. (2002), consideran que los psicópatas no son capaces de experimentar emociones negativas como el miedo y por ello tampoco entienden las emociones negativas de otros. Estos autores sugieren que esto sucede como consecuencia de un funcionamiento anormal del Sistema Límbico y de algunas de sus estructuras como la amígdala, que tiene un rol determinante en la experimentación y regulación emocional y de la conducta. Así se explicaría la ausencia de empatía.

Adicionalmente, múltiples estudios como el de Adolphs et al. (2005), han demostrado que en los Psicópatas hay un procesamiento anormal en el córtex anterior cingulado y la ínsula anterior. Estas, son áreas relacionadas con el reconocimiento y la comprensión de las emociones reflejadas en las expresiones faciales de los otros.

En cuanto al comportamiento depredador, varios autores, entre ellos Blair et al. (2018) han mostrado que los psicópatas poseen una especial sensibilidad ante la recompensa. Al combinar la falta de empatía con esa sensibilidad exagerada a la recompensa, el resultado es la consecución de sus fines sin reparar en los medios.

Varios autores coinciden en que los psicópatas exitosos muestran más habilidad en solución de problemas y aprendizaje de los errores, que los no exitosos debido a un mejor funcionamiento del lóbulo frontal. Esto implica, además menor impulsividad y agresión y mejor capacidad de planificación, organización y ejecución. Los psicópatas no exitosos, a menudo, muestran un volumen reducido del córtex pre-frontal, medial frontal y orbito-frontal. Por otro lado, un sinnúmero de estudios ha demostrado una relación entre el daño en el lóbulo frontal y el comportamiento agresivo. (Lantrip et al., 2016).

\section{PRESENTACIÓN DEL CASO}

María Concepción Ladino, alias "La bruja asesina" ha sido catalogada como una asesina en serie por las autoridades colombianas. Esta mujer nació y creció en Bogotá en la década de 1960. Se hacía llamar la "Hermana María” o “Doña Conchita”, y se le adjudicaron al menos seis crímenes, entre hombres y mujeres; sucedidos durante la década de 1990. El móvil de los asesinatos parece ser la obtención de lucro y réditos económicos de sus víctimas a través de la estafa y la extorción.

De su modus operandi, se conoce que se, ganaba la confianza de las personas a través de trabajos de hechicería y brujería que prometían protección, mejor calidad de vida, ganancias económicas y rentabilidad en negocios; $y$ en general prosperidad como resultado de su influencia espiritual positiva. Esta se transmitía, a las posibles víctimas, a través de pócimas fétidas guardadas en frascos, baños especiales y rituales mágicos.

Ladino aducía poseer poderes especiales, capacidad de predecir el futuro y ser médium espiritual.

El primero de sus crímenes fue perpetrado el 13 de octubre de 1994 después de que la asesina ofreciera una serie de bebidas, baños y hechizos a Carlos, su arrendador por varios meses, con la finalidad de mejorar su salud. La víctima accedió a tomar estos brebajes y a realizar otros rituales por demás extraños, involucrando también a sus tres hijos, después de que Ladino, le convenciera de que estaba demacrado y enfermo; y que ella, a través de estos menjurjes, podía milagrosamente sanarlo.

El día en que se perpetrara el asesinato, Carlos permaneció solo en su habitación por varias horas, hasta que su esposa se percató de que la situación no era normal. Utilizando sugestión y manipulación, Ladino convenció a la pareja del occiso y a su familia que, este último estaba en un trance espiritual y que no podía ser molestado. Posteriormente y debido a la larga espera, la esposa de Carlos entró al cuarto, desobedeciendo a la curandera y se encontró con el cadáver de su esposo tendido en el piso en un charco de sangre. 
Ladino, acabó huyendo del lugar, acusando a la familia del occiso de asesinato. Como consecuencia de esta acción coercitiva, los hijos de Carlos nunca la denunciaron ante las autoridades.

Después de estos acontecimientos, Ladino se trasladó a otro sitio en Bogotá. Allí conoció a un señor, dueño de dos automóviles, al cual también le ofreció sus servicios de hechicería. Estos no surtieron los efectos esperados, debido a esto, la mencionada bruja citó a la víctima para hacerle un último trabajo con el fin de cambiarle el físico y así protegerlo de sus enemigos. Finalmente, este hombre nunca apareció, su esposa interpuso una denuncia ante las autoridades en contra de Concepción Ladino que fue detenida por estafa, pero liberada posteriormente por falta de pruebas.

Tiempo después, la "Bruja Asesina" se trasladó a Bucaramanga, en este lugar se hacía llamar «La Hermana María». Para finales de la década de 1990 conoció a Heidy Forero, una señora con problemas financieros y a quien también ofreció ayudarla. Ladino se la llevó en su carro a un lugar desolado donde la quemó después de dormirla con un somnífero. De esta forma la asesinó.

Como parte de su estrategia por evadir a las autoridades, se trasladó nuevamente a Bogotá, esta vez a un rancho, donde conoció a una mujer que tenía un dinero guardado. A esta le dio escopolamina y aunque no la mató la amenazó de muerte si la denunciaba. Después, se trasladó al barrio Ciudad Jardín donde conoció a una pareja de ancianos a quienes les hurtó quince millones de pesos con engaños y mentiras, ambos fueron asesinados.

Las últimas víctimas de Ladino fueron tres hermanas a quienes les robó trece millones de pesos, también con engaños. Les aseguró que salvaría a su madre de un tumor cancerígeno que tenía en el cuello, la señora finalmente falleció y la bruja les robó el dinero. Las perjudicadas empezaron a presionarle para que les devuelva la plata, como respuesta, la "bruja asesina" citó a las tres hermanas, a las afueras de Bogotá para devolverles el dinero y en este lugar las asesinó a pedradas, con ayuda de otras dos personas.

En 1999, Concepción Ladino fue capturada por la Fiscalía General de la Nación, después de una exhaustiva búsqueda que duró varios meses. Fue condenada a 40 años de prisión. Fue culpada de asesinar a seis personas y de estafar a más de veinte. Como sucede con otros psicópatas, al momento de su captura trató de suicidarse y declaró padecer problemas mentales con el fin de librarse de la condena. Esta estrategia no le dio resultado y en la actualidad la "bruja asesina" cumple su condena en la cárcel del Buen Pastor de la ciudad de Bogotá.

\section{ANÁLISIS}

Al colocar a Ladino, bajo el lente de los criterios diagnósticos descritos en DSM V (2016) se puede afirmar que, ella padece un Trastorno de Personalidad del grupo B, probablemente Antisocial y/o Límite. Esto se puede inferir, a partir del análisis de su comportamiento y de las circunstancias en las que se desarrolló su historial delictivo; y a pesar de la limitada información obtenida, sobre algunas de sus esferas vitales como la familiar, la social y la demográfica. Es evidente que, su dinámica conductual estuvo marcada por el cometimiento de actos imprudentes, erráticos y crueles; algunas veces impulsivos y otras veces cuidadosamente planificados.

En no pocos casos, el accionar de esta mujer acarreó la intoxicación grave de sus víctimas e inclusive la muerte intencional de la mayoría de ellas. Esto hace pensar que además era inescrupulosa, e incapaz de controlar sus impulsos destructivos, puesto que, a sabiendas de que la policía, la estaba buscando, siguió cometiendo crímenes y atracos de manera obsesiva y descontrolada. El cúmulo de errores, dejaron 
un rastro claro, para las autoridades y al final provocaron su detención.

El intento suicida de esta mujer en el momento de su captura, además de sugerir que padece un trastorno límite de personalidad, cuyas características patognomónicas son la falta de control de los impulsos, acusantes y crónicos sentimientos de vacío, los cuales precipitan, en circunstancias de estrés; también corrobora el postulado de Wellons (2012) sobre las psicópatas secundarias. Este afirma que se caracterizan por una impulsividad extrema, agresividad, conductas suicidas y trastorno de estrés postraumático (TEPT).

Para entender la conducta delictiva de María Concepción Ladino, alias "La bruja asesina" es importante analizar, además de la personalidad, el aprendizaje o la socialización, otros factores como la motivación y el "modus operandi. Si bien, los primeros inciden fuertemente en el cometimiento de un delito, no se precipitan de no existir uno o varios motivos en el sujeto, para hacerlo; y un "modo de accionar en determinadas circunstancias. Este último aprendido, en algún momento de la vida. Para Garrido (2007, p.20) el modus operandi o "Modo de hacer" es el conjunto de conductas que constituyen la perpetración del acto criminal, matizando su carácter dinámico.

En el caso de las mujeres violentas, salvo excepciones, se observa una tendencia general hacia un modus operandi que no requiera un uso elevado de la fuerza física (Rovelo y de Santiago, 2020). Esto es coherente con los planteamientos de Rovelo y Borja (2019), según los cuales "La forma más común que tienen las mujeres de ejercer la violencia contra otras personas es el daño psíquico provocado a través del uso de lenguaje degradante, amenazas, chantaje, manipulación, acoso, mentiras, entre otras.

Analizando el modus operandi utilizado por Ladino e identificado en el cometimiento del sinnúmero de acciones engañosas que le fueron imputadas; no se evidenció ejercicio de fuerza física de su parte, pero si chantaje, manipulación, sugestión y en algunos casos coerción. Además, no actuaba sola, otras personas, especialmente varones, colaboraron con ella, especialmente varones.

Esta mujer establecía relaciones interpersonales utilitarias, se ganaba la confianza de sus víctimas, para estudiarlas con cuidado e identificar sus características de personalidad, emocionales y cognitivas, pero sobre todo su condición económica. Posteriormente procedía a timarlas y en varios casos a asesinarlas.

Al hablar de psicopatía, otro factor, importante de análisis, es la motivación del sujeto para la ejecución de la acción dañosa. Pudiendo, esta, ser tan diversa como actos violentos, delitos y mujeres. Según Yugueros (2014) y García (2019), los móviles en las mujeres son efectivamente distintos, a los de los varones. Siendo las principales y casi exclusivas causas de delincuencia femenina, aquellas de tipo sociocultural, relacionadas con pobreza, exclusión social, bajo nivel educativo y falta de recursos. No así en las mujeres Psicópatas, como en el caso de Ladino, en quienes las motivaciones son impulsos primarios que, debido a sus características de personalidad, no saben reprimir o demorar su gratificación, necesitando que esta sea inmediata (Rovelo y de Santiago, 2020).

Kruttschnitt y Carbone-Lopez (2006), citados por Rovelo y de Santiago (2020), consideran que los actos violentos, incluidos los asesinatos ejecutados por mujeres, están motivados por celos, legítima defensa, autoayuda, precipitación victimal lucro económico y/o discusión que derivó en pelea. En su mayoría, son consecuentes a procesos emocionales que, de alguna manera dotan de una razón o sentido más o menos comprensible a la acción.

En las Psicópatas, su accionar violento tiene motivaciones económicas, como en el caso de Ladino o simplemente no obedecen a ninguna 
"lógica” a la hora de ejercer la violencia. Siendo aparentemente inexplicable, impredecible y arbitraria.

De acuerdo a la clasificación propuesta por Holmes y Holmes, citado en (Garrido, 2007, p. 270) Ladino sería del tipo de psicópatas cuya motivación es el lucro económico de sus víctimas. Jamás mostro interés, menos aún empatía por el sufrimiento o dolor generado en ellas $\mathrm{y} / \mathrm{o}$ en sus familiares, tampoco, remordimiento o culpa. Ella recurrentemente justificaba su comportamiento aduciendo ingenuidad y falta de sagacidad, en sus víctimas. Todos estos, mecanismos cognitivos característicos de la personalidad Antisocial y por tanto presentes en los y las psicópatas.

En este sentido y coincidiendo y además con el planteamiento de Sheldon Itzkowitz y Elizabeth F. Howell (2020) Ladino sería un excelente ejemplar de maldad, ya que fue una depredadora y dejó a su paso, destrucción y sufrimiento en las infortunadas víctimas que se cruzaron en su camino. De acuerdo a la Clasificación de Michael y Kelleher (1998) de asesinas por características, armas y víctimas. Ladino es una asesina en serie, no solo por su nivel de crueldad, sino sobre todo porque mató a varias personas con un periodo de enfriamiento entre uno y otro asesinato.

La teoría estructural propuesta por Freud en (1934) explicaría la dinámica asesina de Ladino, como el resultado de la ausencia de tensión entre su yo y su super yo. Ambas, estructuras reguladoras de la conducta y capaces de tamizar la expresión del ello, adaptándolo a las condiciones de realidad del sujeto y a las expectativas culturales. Siendo esto lo más frecuente en personas no Psicópatas, en el comportamiento de Ladino se evidenció lo contrario. Ella no logró adaptarse ni regular su conducta delictiva, misma que se exacerbó en el tiempo, resultando al final en su detención, sentencia y posterior confinamiento en una prisión, por cuarenta años.

Este tipo de situaciones, son vividas con frecuencia por Psicópatas secundarios, los más estudiados y más fáciles de reconocer, debido a que sus vidas están ligadas a procesos judiciales y a dinámicas de persecución de duración variable, meses o años y terminan, en la mayoría de los casos; como en el caso de estudio, con la aprensión de estos sujetos.

A menudo, estas personas cometen una serie de errores a lo largo de su vida delictiva. Como consecuencia de la presión interna creciente que experimentan, incurren en acciones erráticas que boicotean paulatinamente su vida. A esto se suma su impulsividad y falta de reflexividad. Es importante señalar que cognitivamente, como sucede con Ladino, los psicópatas están conscientes de que están transgrediendo la norma y la ley solo que no les importa. Para ellos, como para Ladino, el fin justifica los medios y las posibles consecuencias no representan un freno.

En cuanto a los vínculos familiares primarios de la "bruja asesina" la información documental obtenida no brinda mayores detalles de esta esfera en particular. Sin embargo, se colige que no mantenía relaciones cercanas o estrechas con su familia de origen (padres o hermanos). Parece ser que durante el periodo de tiempo en que ella comete la mayoría de los asesinatos, extorciones y estafas y peregrina por varias ciudades de Colombia, en ningún momento buscó apoyo familiar.

\section{CONCLUSIONES}

Históricamente, la psicopatía como problemática de la personalidad relacionada en la peligrosidad, el conflicto y la transgresión de la norma y la ley ha sido objeto de estudio de la Biología, la Psicología y las Ciencias Sociales. Estas ciencias en colaboración con otras como la Antropología y la Criminología han aportado enormemente en la comprensión de los sujetos que la padecen; y que a lo largo del tiempo han 
sorprendido a la sociedad por la perversidad de sus crímenes. Sin embargo, estos estudios no han sido equitativos en relación a las mujeres, en quienes se ha subestimado esta problemática, considerada casi exclusiva de los varones. Presente únicamente en mujeres consideradas "menos evolucionadas o inferiores", evidenciando un análisis sesgado que las discrimina y sataniza.

La Psicopatía no puede comprenderse y explicarse desde un solo enfoque. Dada su complejidad, son varios los factores intrínsecos y extrínsecos al sujeto, que inciden en el aparecimiento y desarrollo de este trastorno. En el caso de la Psicopatía femenina, los estudios son relativamente escasos. Las dimensiones genéricas a través de las cuales se analiza este fenómeno en el tiempo están subordinadas a los distintos paradigmas y modelos científicos y sociales dominantes; los mismos que, esencialmente son falocéntricos y por lo tanto invisibilizan las condiciones específicas que inciden en su aparecimiento en las mujeres.

Hasta la actualidad, la Psicopatía es considerada, un trastorno esencialmentemasculino. Su prevalencia en relación al padecimiento en mujeres es de 6 a 1, sin embargo, el número de mujeres en el mundo que presentan este trastorno es cada vez mayor. Cometen crímenes tan perversos como los ejecutados por Psicópatas varones, siendo su principal motivación, el lucro económico. El caso de María Concepción Ladino, alias "La bruja asesina es un ejemplo claro, que además devela un modus operandi diferente al de los varones. Siendo sus crímenes perversos y atroces, no hay indicios de violencia física ejecutada por ella, pero si la presencia de manipulación chantaje, sugestión, coerción, astucia y mucha maldad.

La Psicopatía, como se evidenció en la persona, objeto de estudio en este trabajo, provoca un desajuste muy severo a nivel adaptativo y afecta profundamente el desempeño del sujeto en todas las esferas de su vida. Las mujeres psicópatas, con frecuencia, presentan otros trastornos de personalidad como el Límite, o el Histriónico; del Estado de ánimo como bipolaridad; y otros relacionados con el Consumo de Sustancias Psicoactivas, cada vez más presentes en ellas.

El vínculo afectivo inicial establecido entre el neonato y sus cuidadores primarios parece ser de vital importancia en la constitución de la estructura psíquica y la personalidad. Un vínculo desorganizado, ansioso y/o evitativo construido entre las niñas y sus madres se considera un factor de riesgo para desarrollar un trastorno Psicopático en la adultez. Esta forma de vinculación afectiva se ha relacionado directamente con vivencias intensas y frecuentes de violencia, negligencia o maltrato de cualquier tipo, protagonizadas habitualmente por padres o madres con problemas mentales severos y/o que padecen trastornos de personalidad, y/o de consumo de Sustancias Psicoactivas.

Los trastornos conocidos como externalizantes, afines a los que presenta María Concepción Ladino, aquellos que se manifiestan a través de comportamientos y conductas desadaptativas y/o ilegales, son más frecuentes en varones que en mujeres. Estas últimas, con mayor frecuencia, padecen trastornos internalizantes como Ansiedad, Depresión, Bipolaridad y Estrés Postraumático, a modo de consecuencia de vivencias traumáticas de cualquier tipo, Esto también podría explicar la diferencia numérica existente entre mujeres y hombres Psicópatas.

Desde la teoría Estructural del Aparato psíquico se concluye que, una adecuada estructuración e integración del ello, el yo y el súper yo, permite que las personas desarrollen empatía y capacidad de controlar sus impulsos. Ambos, mecanismos, indispensables para la adaptación y la regulación de la conducta y el comportamiento. Lamentablemente, están ausentes en María Concepción Ladino, como en los psicópatas en general. 
En cuanto a la incidencia de los aspectos neurobiológicos, las evidencias no demuestran la existencia de diferencias significativas entre los hombres y las mujeres psicópatas. Las mismas sugieren que la influencia ambiental es determínate en el comportamiento delincuencial de las mujeres y que está relacionado con la pobreza y la marginación social, no así, la Psicopatía.

Varios autores sugieren que el sistema límbico, como la base de la regulación emocional y por sus conexiones con el lóbulo frontal y el cíngulo, presenta en los psicópatas, un funcionamiento anormal. Esta particularidad les dificulta entender las emociones negativas, pero también provoca una sensibilidad exagerada en el sistema de recompensa. Parece ser que ambas condiciones son las responsables principales de la ausencia de empatía y la consecución de los objetivos sin importar los medios.

El aprendizaje por modelamiento, podría explicar, al integrarlo con elementos de análisis de otros enfoques, la incidencia del ambiente y los reforzadores de las conductas antisociales, en el comportamiento de María Concepción Ladino a lo largo de su vida. Normalizado mecanismos violentos de resolución de conflictos, mismos que en el tiempo, desde su visión retorcida de la vida, y las relaciones, debieron ser interpretados como efectivos. Probablemente, ella, los perfeccionó, en medida que el asesinato se convertía en un mecanismo obsesivo y descontrolado para salir de los problemas y que al final, la llevó a ser descubierta y posteriormente a la cárcel.

\section{REFERENCIAS}

Adolphs, R., Gosselin, F., Buchanan, T. W., Tranel, D., Schyns, P., y Damasio, A. R. (2005). A mechanism for impaired fear recognition after amygdala damage. Nature, 433(7021), 68-72

Akers, R. L. (1997). Criminological theories. Los Angeles: Roxbury Publishing Company
Bandura, A. (1987b). Teoría del aprendizaje social. Madrid: Espasa-Calpe.

Bandura, A. (1987a). Pensamiento y acción: Fundamentos sociales. Barcelona: Martínez Roca

Bandura, A. Y Ribes, R. (1975). Modificación de Conducta: Análisis y Agresión Yde La Delincuencia. México: Trillas

Bandura, A. Y Walters, R.H. (1983). Aprendizaje social y desarrollo de la personalidad. Madrid: Alianza Popular

Birmauer N., Veit, R., Lotze, M., Erb, M., Hermann, C., Grod, W. y Flor, H. (2005). Deficient fear conditioning in psychopathy: A functional magnetic resonance imaging study. Archives of General Psychiatry, 62, 799-805

Burguess, R.L. y Akers, R.L. (1966). A differenctial association-reinforcement theory of criminal behabior. Socail problems, 14, 128-147

Carabellese, F., Felthous, A. R., La Tegola, D., Rossetto, I., Franconi, F., Lucchini, G. Y Catanesi, R. (2020). Female psychopathy: a descriptive national study of socially dangerous female NGRI offenders. International Journal of Law and Psychiatry, 68

Chaves, A. R. (2012). Masculinidad y feminidad. ¿De qué estamos hablando? Revista electrónica Educare, 16. 5-13

Código Penal [CP]. Ley Orgánica 10/1995. Arts. 20.1 y 21.1. 23 de noviembre (España)

Constant, C. (2016). Pensar la violencia de las mujeres. La construcción de la figura delincuente. Política y Cultura (46), 145-162

Dawn, C. (2006). "Ceguera de género. La falta de consideración de las delincuentes femeninas por parte de la Criminología". En Francisco Bueno Arús, José Luis Guzmán Dalbora, Alfonso Serrano Maíllo (Coord.). Derecho penal y criminología como fundamento de la política criminal: estudios en homenaje al profesor Alfonso Serrano Gómez. Madrid. Dykinson, pp. 171-183

Deficient fear conditioning in psychopathy: A functional magnetic resonance imaging study. Archives of General Psychiatry, 62, 799-805

DSM (2016). Manual Diagnóstico y Estadístico de los Trastornos Mentales de la Asociación Americana de Psiquiatría 
Freud, S. (1964). Splitting of the ego in the process of defense. En The standard edition of the complete psychological works of Sigmund Freud (Vol. XXIII, pp. 271-278)

García, L. (2019). Fenomenología de la delincuencia femenina en España y teorías criminológicas (Trabajo de Fin de Grado). Universitat Jaume I, Castellón

Garrido, V. (2007). La mente criminal. La ciencia contra los asesinos en serie. Barcelona, Planeta

Garrido, V. (2012). Perfiles criminales: un recorrido por el lado oscuro del ser humano. Barcelona, Ariel

Garrido, I. (2019). Criminalidad femenina. Una aproximación al perfil de la asesina en serie. Revista de Criminología, Psicología y Ley, 1(1), 57-98

Itzkowitz, S. y Howell, E. (Eds). (2020). Psychoanalysts, psychologists and psychiatrists discuss psychopathy and human evil. Routledge

Kraepelin E.Psychiatrie: Ein Lehrbuch. 7a ed. Leipzig: Barth; 1903

Kaufman, I. (1958). Panel reports: Superego development and pathology in childhood. Journal of the American Psychoanalytic Association, 6, 540-551

Lantrip, C., Towns, S., Roth, R. M. y Giancola, P. R. (2016). Psychopathy traits are associated with self-report rating of executive functions in the everyday life of healthy adults. Personality and Individual Differences, 101, 127-131

Lima Malvido, M. (1991)Criminalidad femenina. Teorías y reacción social. México: Porrúa

Lombroso, Cesar y Ferrero, William (1894). The female offender. New York. Philosophical Library

Lopez María (2020). Revista de Criminología, Psicología y Ley. Vol. 4. Septiembre

Maurer, J. M., Steele, V. R., Edwards, B. G., Bernat, E. M., Calhoun, V. D. \& Kiehl, K. A. (2016). Dysfunctional error-related processing in female psychopathy. Social Cognitive and Affective Neuroscience, 11(7), 1059-1068.
Prichard JC. (1835). A treatise on insanity and other disorders affecting the mind. London, UK: Sherwood, Gilpert \& Piper

Rovelo, N. C. y Borja, D. (2019). Aproximaciones psicoanalíticas sobre las mujeres que ejercen la violencia y la delincuencia. Revista de Criminología, Psicología y Ley, 2 (1), 133-152

Rovelo, N. C. y Santiago, F. J. de (2020). La Tríada Oscura femenina: violentas, psicópatas y delincuentes. F. J. de Santiago, N. C. Rovelo y L. M. Sánchez. Psicopatía: un enfoque multidisciplinar. Madrid, McGraw Hill

Santillan Esqueda, M (2016) Instituto Nacional de Ciencias Penales Investigación Magisterio Nacional \#113 Centro Talpan, Ciudad de México 14000, México

Shapiro, D. (1965) Neurotic styles. Basic Books

Sprague, J., Javdani, S., Sadeh, N., Newman, J. P. y Verona, E. (2012). Borderline Personality Disorder as a female phenotypic expression of psychopathy? Personality Disorders-Theory Research and Treatment, 3(2), 127-139

Stone, M. (2020). The Place of Psychopathy Along the Spectrum of Negative Personality Types. En S. Itzkowitz y E. Howell (Eds.), Psychoanalysts, psychologists and psychiatrists discuss psychopathy and human evil (pp. 82-106). Routledge

Wellons, S. (2012). The devil in the boardroom: Corporate psychopaths and their impact on business. PURE Insights, 1 (Article 9), 42-45

Yugueros, A. J. (2014). La delincuencia femenina. Una revisión teórica. FORO. Revista De Ciencias Jurídicas Y Sociales, Nueva Época, 16(2), 311316 